\title{
PURIFICATION OF FINE POWDERS BY A SUPERCONDUCTING HGMS WITH VIBRATION ASSISTANCE
}

\author{
YANMIN WANG ${ }^{\mathrm{a}, *}$, ANN-CATHRINE JOHANSSON ${ }^{\mathrm{a}}$, \\ ERIC FORSSBERG ${ }^{\mathrm{a}}$ and BILLY CHAN ${ }^{\mathrm{b}}$ \\ ${ }^{a}$ Department of Chemical and Metallurgical Engineering, \\ Lulea University of Technology, S-971 87, Luleå, Sweden; \\ ${ }^{\mathrm{b}}$ Carpco Division, Outokumpu Technology Ltd., Langley, \\ Berkshire, SL3 6DA, United Kingdom
}

(Received 4 April 2000; In final form 25 April 2000)

In this study, a superconducting high gradient magnetic separator (HGMS) with a matrix vibration system in dry mode was utilised to purify fine calcite and quartz powders smaller than $38 \mu \mathrm{m}$. The effects of the operating parameters (particle size, magnetic field/average air velocity $\left(B_{0} / V_{0}\right)$, the amplitude of vibration as well as the aperture size of the expanded metal matrix) have been presented. The mechanicallybased matrix vibration with the air blowing was recognised to be effective for dry purification of fine powdered materials at high magnetic fields. The function of the matrix vibration has been discussed. In addition, the results have been empirically correlated with the operating parameters used for the purification in the separator.

Keywords: Superconducting magnetic separator; Magnetic separation; HGMS; Purifcation; Industrial minerals; Powder; Vibration

\section{INTRODUCTION}

Significant nature of the dry HGMS technology for the treatment of fine powders is well known. The formation of the aggregates/clusters and the powder coating cause the matrix clogging and thus poor selectivity of separation. One approach to minimise this negative effect

*Corresponding author. 
is a vibration of the magnetised matrix by means of either an alternating current or a mechanical motion in the separator. Previous work on this aspect mainly focused on the matrix vibration in wet or dry HGMS using an alternating current [1-5]. For instance, Yu [1] reported that the alternating current coils installed on the terminals of two magnetic poles were utilised to excite the vibration of the matrix when a kaolin powder was treated in the dry HGMS. His results showed that this method reduced mechanical entrapment and thus increased the efficiency of separation. Mechanically based vibration is another approach [5]. Lateral mechanical vibration can be provided either by an eccentric rotating shaft driven by a variable speed motor or by the regular rapping of the separation chamber by a vibrator.

The present work deals with a study of dry purification of fine calcite and quartz powders smaller than $38 \mu \mathrm{m}$ using a superconducting HGMS (CRYOFLOW) with mechanically based matrix vibration in a dry mode.

\section{EXPERIMENTAL}

\subsection{Materials}

Relatively pure calcite, quartz and hematite, whose purity was established by X-ray diffraction and by chemical assay, were used in this study. Calcite was obtained from OY Nordkalk AB, Finland. Quartz was obtained from Norwegian Crystallites, Norway and hematite was from Malmberget, LKAB, Sweden. The minerals were first ground to $<70 \mu \mathrm{m}$ by a porcelain mill and then classified into $<38>20,<20>10$ and $<10 \mu \mathrm{m}$ fractions by sieves and a cyclonsizer, respectively. Each calcite or quartz fraction was mixed with 3 percent of the same size fraction of hematite. The iron content in the mixture was $3.14 \% \mathrm{Fe}_{2} \mathrm{O}_{3}$ (or $2.20 \% \mathrm{Fe}$ ).

\subsection{The Superconducting Magnetic Separator System}

The superconducting dry high gradient magnetic separator named CRYOFLOW Model 5T/75CF (Carpco Division, Outokumpu 
Technology Ltd., UK) was utilised in the study. Figure 1 shows the principle of the system. This unit is a self-contained laboratory/pilot system for separation of dry powdered materials of low magnetic susceptibilities. The system consists of a superconducting magnet producing any required magnetic field strength between 0 and 5 Tesla, a vibrating pneumatic pressurised feeder system and a vertical reciprocating canister with a mechanical vibrator for automatic processing.

The matrix used was an expanded metal with an aperture size of $4 \times 8 \mathrm{~mm}^{2}$ or $2.5 \times 4.0 \mathrm{~mm}^{2}$, which was packed into the canister $62 \mathrm{~mm}$ in diameter and $1000 \mathrm{~mm}$ long, so that the matrix occupied one end of the section, $100 \mathrm{~mm}$ length, inside the canister. The spacing between the expanded metal discs was $3 \mathrm{~mm}$. A pneumatic pressurised feeder system with vibration was used to deliver the fine particles into the canister. The vibrator was installed on the top of the canister. The vibration was activated by means of a diode component in the electrical circuit supply attached to the springs fitted vibrating unit and connected to an AC regulating transformer. The amplitude of vibration for the vibrator was controlled by the transformer in the range from 0 to 125 volts at the mains frequency of $50 \mathrm{~Hz}$.

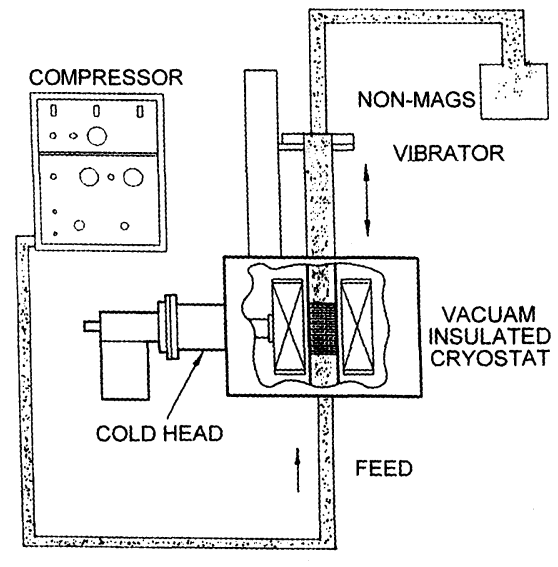

PROCESS

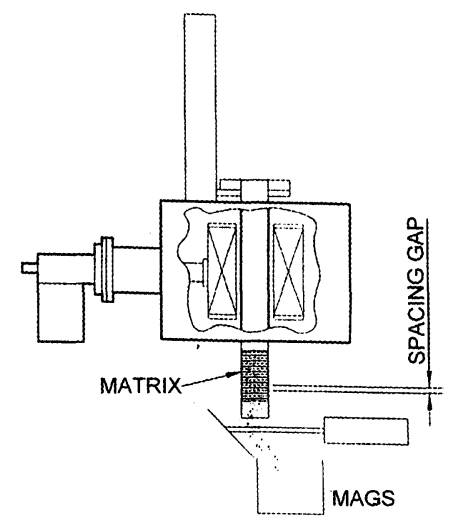

MAGNETICS PURGE

FIGURE 1 The diagram of the CRYOFLOW system. 


\subsection{The Experimental Design and Procedure}

\subsubsection{Calcite-Hematite Powder}

Statistical experimental design $L_{18}\left(2^{1} \times 3^{3}\right)$ was employed to perform the tests with mixed calcite-hematite powders, as shown in Table I. The independent variables with various levels were the aperture size of the expanded metal $\left(\mathrm{mm}^{2}\right)$ fraction size $(\mu \mathrm{m})$, magnetic field $\left(B_{0}\right)$ /average air velocity $\left(V_{0}\right)\left(\right.$ Tesla $\left./ \mathrm{m} \mathrm{s}^{-1}\right)$ and the amplitude of the vibration with the frequency of $50 \mathrm{~Hz}(\mathrm{~mm})$. The responses or dependent variables for the statistical analysis of the results were the iron reduction rate in percentage and the mass yield of the non-magnetic product.

\subsubsection{Quartz-Hematite Powder}

Experiments with the mixed quartz-hematite powder were designed by a statistical multiple-factorial with a mixed levels approach [6]. The

TABLE I Experimental design for mixed calcite-hematite powder, $L_{18}\left(2^{1} \times 3^{3}\right)$

\begin{tabular}{|c|c|c|c|c|}
\hline \multirow[b]{2}{*}{$\begin{array}{l}\text { Test } \\
\text { no }\end{array}$} & \multicolumn{2}{|r|}{ Variable } & \multicolumn{2}{|l|}{ level } \\
\hline & $\begin{array}{c}\text { Aperture size } \\
\text { of matrix, } \mathrm{mm}^{2}\end{array}$ & $\begin{array}{c}\text { Size of } \\
\text { fraction, } \mu m\end{array}$ & $\begin{array}{c}B_{0} / V_{0} \\
T / m s^{-1}\end{array}$ & $\begin{array}{l}\text { Amplitude of } \\
\text { vibration, } \mathrm{mm}\end{array}$ \\
\hline 1 & 1 & 1 & 1 & 1 \\
\hline 2 & 1 & 1 & 2 & 2 \\
\hline 3 & 1 & 1 & 3 & 3 \\
\hline 4 & 1 & 2 & 1 & 1 \\
\hline 5 & 1 & 2 & 2 & 2 \\
\hline 6 & 1 & 2 & 3 & 3 \\
\hline 7 & 1 & 3 & 1 & 2 \\
\hline 8 & 1 & 3 & 2 & 3 \\
\hline 9 & 1 & 3 & 3 & 1 \\
\hline 10 & 2 & 1 & 1 & 3 \\
\hline 11 & 2 & 1 & 2 & 1 \\
\hline 12 & 2 & 1 & 3 & 2 \\
\hline 13 & 2 & 2 & 1 & 2 \\
\hline 14 & 2 & 2 & 2 & 3 \\
\hline 15 & 2 & 2 & 3 & 1 \\
\hline 16 & 2 & 3 & 1 & 3 \\
\hline 17 & 2 & 3 & 2 & 1 \\
\hline 18 & 2 & 3 & 3 & 2 \\
\hline \multicolumn{2}{|l|}{ Level } & 1 & 2 & 3 \\
\hline \multirow{4}{*}{\multicolumn{2}{|c|}{$\begin{array}{l}\text { Aperture size of matrix, } \mathrm{mm}^{2} \\
\text { Fraction size, } \mu \mathrm{m} \\
B_{0} / V_{0}, \mathrm{~T} / \mathrm{m} \mathrm{s} \mathrm{s}^{-1} \\
\text { Amplitude of vibration, } \mathrm{mm}\end{array}$}} & $2.5 \times 4.0$ & $4.0 \times 8.0$ & \\
\hline & & $<10$ & $<20>10$ & $<38>20$ \\
\hline & & $1 / 0.5$ & $3 / 0.5$ & $5 / 0.5$ \\
\hline & & 0 & 1.0 & 2.5 \\
\hline
\end{tabular}


aperture size of the expanded metal used was $2.5 \times 4.0 \mathrm{~mm}^{2}$. The independent variables involved:

- Size fraction, $<10,<20>10$ and $<38>20 \mu \mathrm{m}$;

- $B_{0} / V_{0}, 2 / 0.5$ and $5 / 0.5$ Tesla $/ \mathrm{m} \mathrm{s}^{-1}$;

- Amplitude of vibration with the frequency of $50 \mathrm{~Hz}, 0$ and $2.5 \mathrm{~mm}$.

Each powder was fed via the batch-feeding atomiser unit from the bottom of the magnet and was processed in the canister containing the magnetised expanded metal matrix. The retention of the magnetic particles occurred on the expanded metal matrix in the longitudinal configuration. The loading on the expanded metal matrix, defined as the mass of the feed divided by the working volume of the matrix, was $330 \mathrm{~kg} \mathrm{~m}^{-3}$. The purification of each powder was performed with or without the matrix vibration. The non-magnetic fraction was collected in a filter-paper bag during the processing. After the separation, the reciprocating canister mounted within the bore of the magnet moved the trapping zone out of the high gradient magnetic field, allowing the collected magnetic fraction to be released via an automatic chute. All samples collected were weighed for assaying.

The particle size was analysed using X-ray Sedimentometer SediGraph 5100 (Micromeritics Co., USA). The magnetic susceptibility of the material fraction was determined by the JM magnetic susceptibility balance (Oxford Instrument Ltd., UK). The brightness of calcite powders was measured by Zeiss Photoelectric Reflectance Photometer (ELREPHO). The primary standard, barium sulphate, and the internal standard were used to calibrate the instrument at $\lambda=457 \mathrm{~nm}$ (R457 filter with white light).

\section{RESULTS AND DISCUSSION}

\subsection{Study on Mixed Calcite-Hematite Powder}

\subsubsection{Analysis of Variance}

Experiments on four major parameters (the size fraction, the aperture the size of matrix, $B_{0} / V_{0}$ and the amplitude of vibration) were carried out. Considering a significant difference at the confidence level of $95 \%$ $(\alpha<0.05)$, the Turky significant differences test [6] in the analysis of 
variance (ANOVA) was used to investigate difference between two aperture sizes of the expanded metal matrices, the difference among three fractions, the size difference among three levels of $B_{0} / V_{0}$ as well as the difference among three levels of the amplitudes of vibration. Since the designed experiments were not replicated, it was assumed that the multi-factor interaction effects would be negligible. The ANOVA was used to examine the null hypothesis that the variation of each independent variable at various levels has no effect on the iron removal to the magnetic product (\%) and the mass yield of the non-magnetic product (wt. \%).

The results of ANOVA for the iron removal (\%) in Table II(a) demonstrate that the probability of the null hypothesis that the fraction size, $B_{0} / V_{0}$ as well as the aperture size of the matrix have no significant effects is $0.0019,0.0261$ and 0.0286 , respectively. This means that the fraction size, $B_{0} / V_{0}$ and the aperture size of the matrix

TABLE II(a) Results of ANOVA for dry purification of the calcite-hematite mixture by a superconducting $\mathrm{HGMS}, \mathrm{Fe}_{2} \mathrm{O}_{3}$ removal

\begin{tabular}{lrrrrc}
\hline Variable & $\begin{array}{c}\text { Sum of } \\
\text { squares }\end{array}$ & Df & $\begin{array}{r}\text { Mean } \\
\text { square }\end{array}$ & F-ratio & Probability \\
\hline Fraction size, $\mu \mathrm{m}$ & 1059.82 & 2 & 529.91 & 12.55 & 0.0019 \\
$B_{0} / V_{0}$, Tesla $/ \mathrm{m} \mathrm{s}^{-1}$ & 398.48 & 2 & 199.24 & 4.72 & 0.0361 \\
Aperture size of matrix, $\mathrm{mm}^{2}$ & 275.97 & 1 & 275.97 & 6.53 & 0.0286 \\
Amplitude of vibration, $\mathrm{mm}$ & 25.54 & 2 & 12.77 & 0.30 & 0.7456 \\
Residual & 422.33 & 10 & 42.23 & & \\
Total (corrected) & 2160.35 & 17 & & & \\
\hline
\end{tabular}

All F-ratios are based on the residual mean square error.

TABLE II(b) Results of ANOVA for dry purification of the calcite-hematite mixture by a superconducting HGMS, Mass yield of non-magnetic product

\begin{tabular}{lrrrrc}
\hline Variable & $\begin{array}{c}\text { Sum of } \\
\text { squares }\end{array}$ & Df & $\begin{array}{r}\text { Mean } \\
\text { square }\end{array}$ & F-ratio & Probability \\
\hline Fraction size, $\mu \mathrm{m}$ & 1086.89 & 2 & 543.44 & 5.95 & 0.0199 \\
$B_{0} / V_{0}$, Tesla $/ \mathrm{m} \mathrm{s}^{-1}$ & 106.94 & 2 & 53.47 & 0.59 & 0.5749 \\
Aperture size of matrix, $\mathrm{mm}^{2}$ & 226.35 & 1 & 226.34 & 2.48 & 0.1465 \\
Amplitude of vibration, $\mathrm{mm}$ & 5448.52 & 2 & 2724.2 & 29.82 & 0.0001 \\
Residual & 913.46 & 10 & 91.35 & & \\
Total (corrected) & 8302.71 & 17 & & & \\
\hline
\end{tabular}

All F-ratios are based on the residual mean square error. 
are the primary important variables among the parameters studied. The variation of each parameter dramatically influences the reduction of $\mathrm{Fe}_{2} \mathrm{O}_{3}$ by the superconducting HGMS. The probability for the amplitude of vibration is $74.56 \%$. This proves the hypothesis that its variation does not affect the results of the iron removal from the mixture. The effect of vibration has not been demonstrated to affect the iron reduction significantly from the statistical point of view. This is because the iron oxide particles remain in the matrix in the absence of the matrix vibration due to the mechanical entrapment, leading to a poor selectivity of the magnetic separation.

Table II(b) gives the results of ANOVA of the parameters studied in terms of the reciprocal of the mass yield into the non-magnetic product. The matrix vibration has a statistically significant impact on the mass yield, and its probability is 0.0001 . The other important parameter becomes the fraction size. The probability for this parameter to have no effect for the null hypothesis is $1.99 \%$. The matrix vibration and the fraction size both are the most important factors, which influence the mass yield into the non-magnetic product obtained in the CRYOFLOW system. $B_{0} / V_{0}$ has no effect on the variation of the mass yield as the probability is $57.49 \%$.

\subsubsection{Particle Size and $B_{0} / V_{0}$}

Figure 2 shows the results obtained from different size fractions of the mixture by dry HGMS. The iron reduction drops and the iron content of the non-magnetic product increases with the decreasing fraction size. Also, the mechanical entrapment of particles in the matrix increases significantly for the fraction between 20 and $10 \mu \mathrm{m}$ and the fraction smaller than $10 \mu \mathrm{m}$. The entrapment increases with the decreasing particle size, which leads to the reduction of the efficiency of separation. One of the reasons for these results is that the probability of capturing fine hematite particles by a certain size of the magnetised matrix is reduced when the size of particle is decreased. The other reason is that the finer particles tend to aggregate due to the inter-particle surface forces and the powder coating due to the adhesive forces between the particles and the matrix element/wall, which diminishes the selectivity of magnetic separation, particularly in the absence of the matrix vibration. 

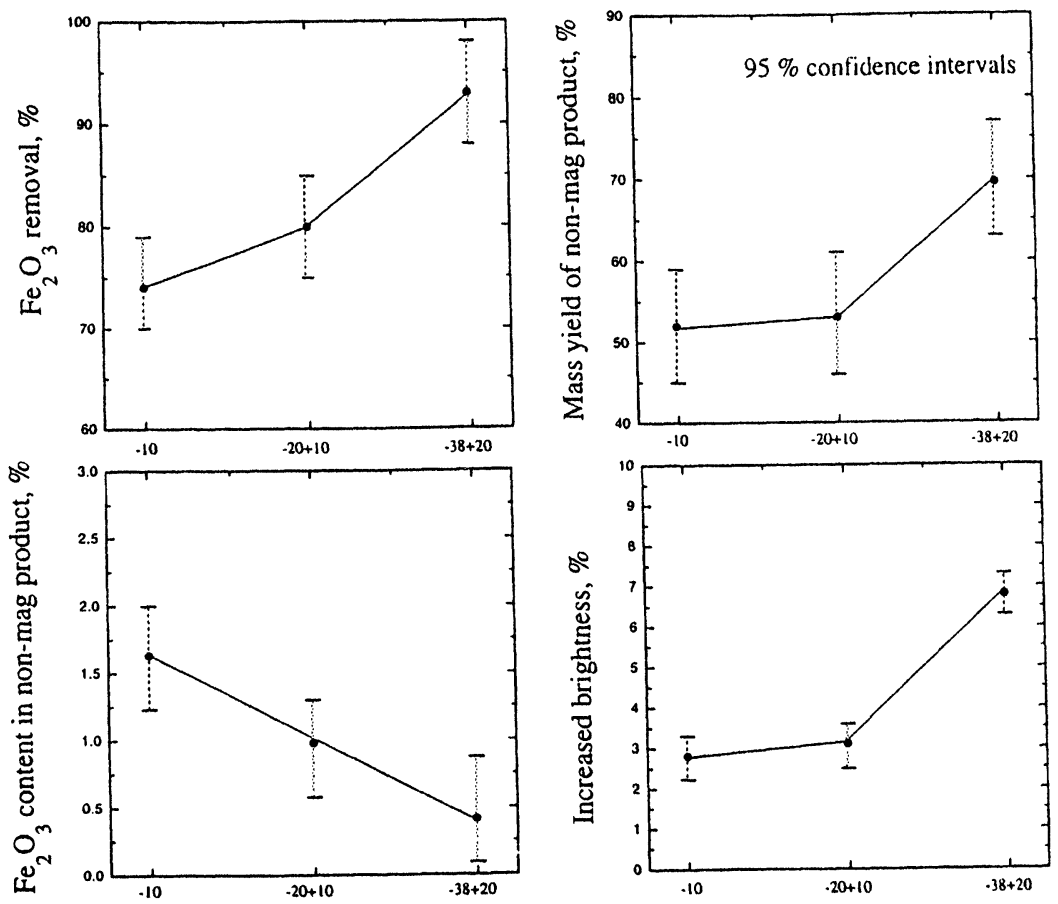

Size of fraction, $\mu \mathrm{m}$

FIGURE 2 The results of purification of various size fraction of mixed calcitehematite powders by the CRYOFLOW system.

The capture process is mainly governed by the interplay of the magnetic and drag forces on a fine magnetic particle. A fine particle in the separator moves under the influence of two force fields, the field due to the magnetised matrix, and the fluid field. Figure 3 shows the results of the purification obtained at various values of $B_{0} / V_{0}$. An increase in $B_{0} / V_{0}$ leads to a decrease in the $\mathrm{Fe}_{2} \mathrm{O}_{3}$ content in the nonmagnetic product. However, little variation in the mass yield of the non-magnetic product occurs in the range of $B_{0} / V_{0}$.

Consider the role of the forces on spherical magnetic particle in the vicinity of a magnetised matrix element. As the particle approaches this element, the magnetic field exerts a force on the particle. Work is therefore done on the particle by the magnetic field of the matrix element. Whenever the motion of the particle is made to deviate from the fluid flow direction, work must be done against the drag force. This energy will be supplied by the magnetic field. If the magnetic field 

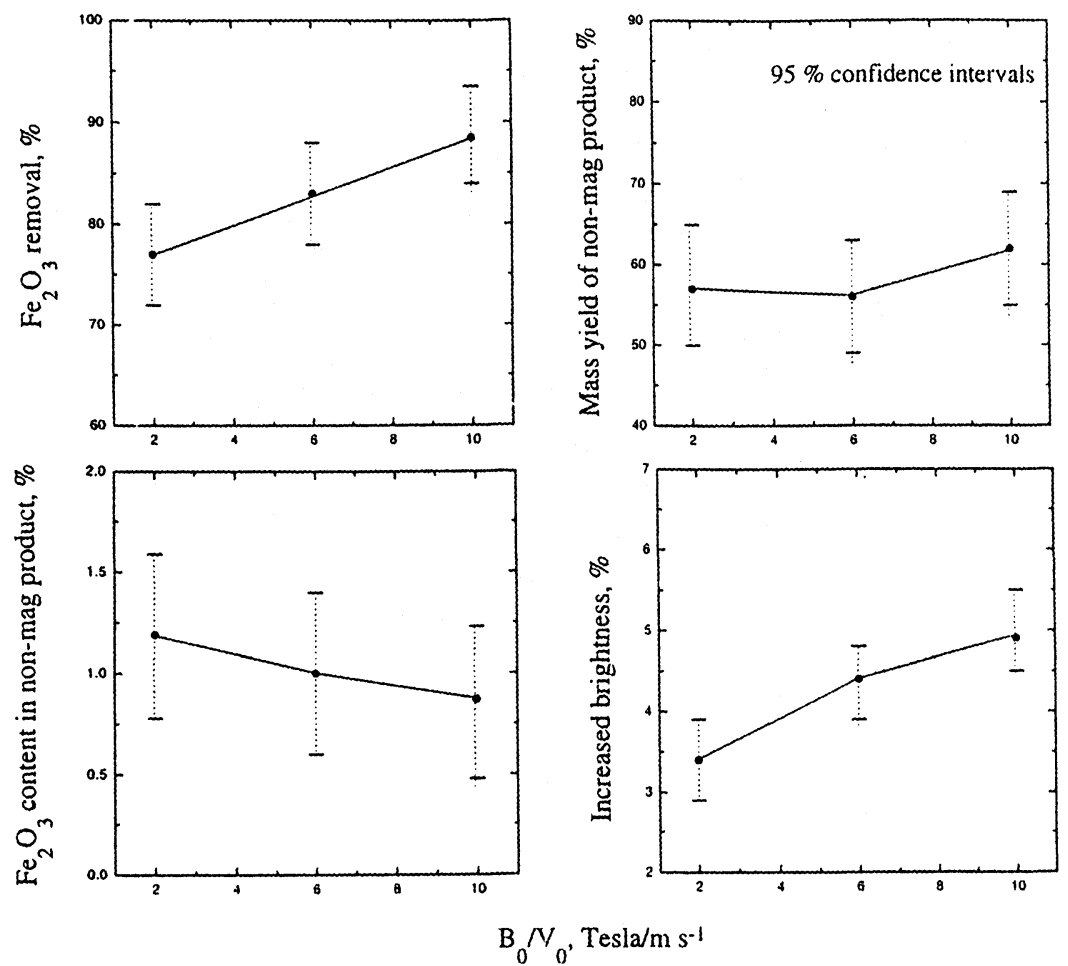

FIGURE 3 The results of purification of mixed calcite-hematite powders by the CRYOFLOW system at various values of $B_{0} / V_{0}$.

cannot supply sufficient energy, the particle will not be captured. For very fine particles, the drag force is large compared to the magnetic traction force. In turn, the relative magnitudes of the magnetic energy and the work necessary to be done against the drag force will govern the capture. Furthermore, the surface interaction energy for the particle-particle and particle-matrix element systems become significant in governing the capture and the transportation of particles through the matrix.

\subsubsection{Matrix Vibration}

Figure 4 shows the experimental results with and without matrix vibration. The mass yield into the non-magnetic product was significantly increased when the vibration with amplitude of 1 or $2.5 \mathrm{~mm}$ (at the main frequency of $50 \mathrm{~Hz}$ ) was used. Also, the vibration 

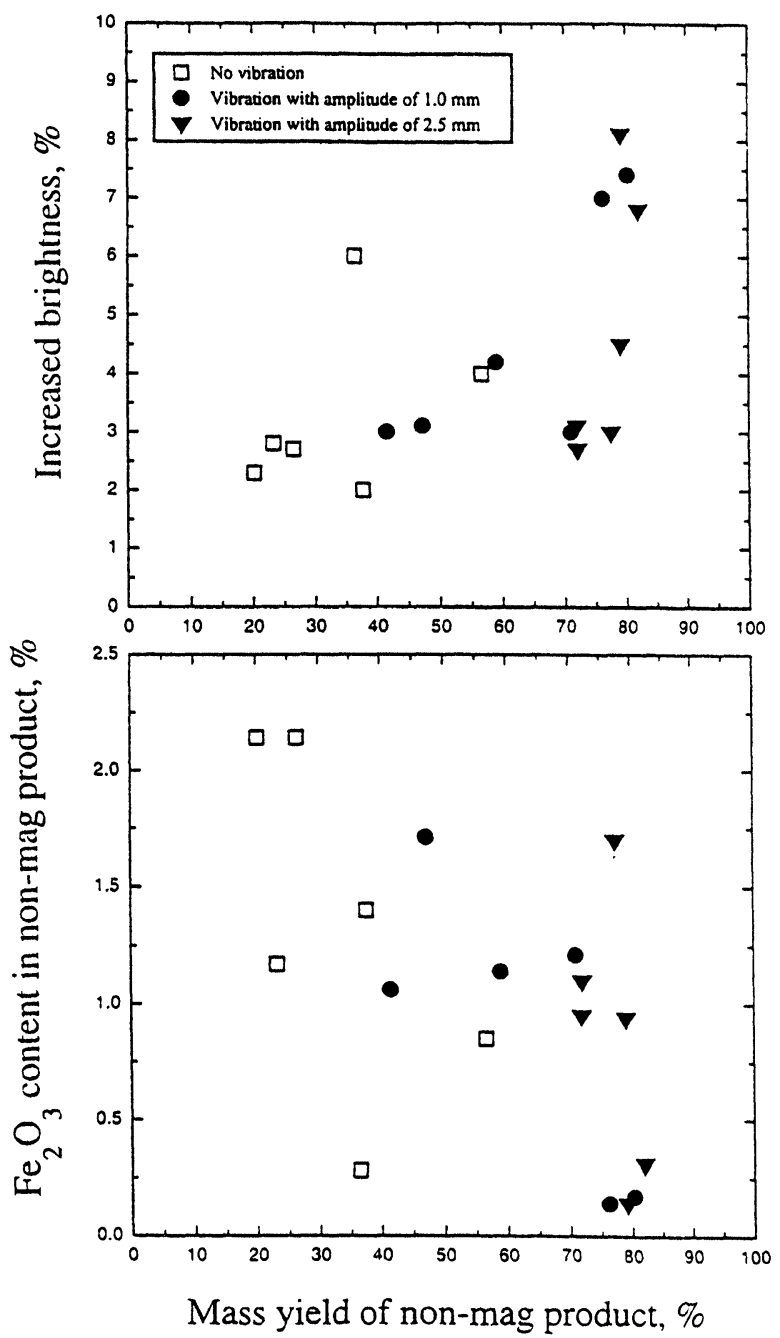

FIGURE 4 The results of purification of mixed calcite-hematite powders by the CRYOFLOW system with or without the matrix vibration.

of the matrix reduces the $\mathrm{Fe}_{2} \mathrm{O}_{3}$ content in the non-magnetic product and improves its brightness. However, a small variation in the percentage of the iron removal into the magnetic fraction appears when the matrix vibration is not used. This insignificance is due to the fact that most magnetic particles are entrapped mechanically in the 
matrix in the absence of matrix vibration rather than by the magnetic capture.

The particle entrapment in the matrix can be of the mechanical or magnetic origin or both. The mechanical entrapment occurs by the capture of particles on the surface of the matrix, in the pore spaces and in irregularities of the magnetic particle deposit on the matrix [7]. The distribution of airflow through the matrix is uneven due to the resistance of the matrix, and becomes higher with the particles gradually accumulated on the surface during the processing. This causes the dislodgement of the non-magnetic particles remaining in the matrix, especially at a lower airflow. The main reason for the mechanical entrapment is the existence of a large amount of finer particles in the feed. The finer particles readily form larger aggregates/ clusters due to the surface forces in the inter-particle system and cause the powder coating due to the surface forces in the particle-wall/ matrix element system. As a consequence of the adhesion particleparticle and particle-matrix or particle-wall, the selectivity of the separation will be reduced. The matrix is readily entrapped with large aggregates/clusters. The intensive vibration can minimise the clogging effect of the aggregates/clusters.

Also, since the hetero-agglomeration between non-magnetic and magnetic particles in air occurs due to the forces of adhesion, the nonmagnetic particles in the particle deposit dislodge in the matrix. The non-magnetic particles can be released from the deposit by means of the mechanically-based vibration of the matrix. The detachment of the non-magnetic particles depends not only on the air flow velocity, but also on the position of the surfaces of matrix/wall relative to the axis of the flow, i.e., the angle at which the flow meets the surface. Vibration can alter the position of the non-magnetic particles in the deposit and enhance their release from the deposit.

The detachment of non-magnetic particles on the surfaces of matrix/ wall can be improved by mechanical vibration. The detachment from the surfaces depends on the particle size. It becomes more difficult for finer particles to escape from the surfaces due to their high adhesive forces. It was found [8] that small powdered particles, say smaller than $50 \mu \mathrm{m}$, the adhesive force of which greatly exceeds the particle weight, are not removed readily from the surfaces by air flow. To improve the efficiency with which the adhering particles are removed, an 
intensification of a auxiliary particle-removing process is suggested, for instance, a combination of the air blowing and mechanical vibration can be used to remove the particles.

The harmonic motion of mechanical vibration in the vertical direction is given by $y(t)=A \cos (2 \pi \nu t+\alpha)$, where $\nu$ is the circular frequency, $A$ is the amplitude of vibration, $t$ is the time and $\alpha$ is the phase angle. Clearly, the motion is proportional to the amplitude. Vibration at a suitable amplitude with a certain frequency $(50 \mathrm{~Hz})$ enhances the release of the particles from the matrix can be pneumatically removed by the air flow. The results show that the mass yield and the iron content of the non-magnetic product increase with the amplitude of vibration at a certain frequency.

It can be concluded that the matrix vibration can, by reducing the matrix clogging, enhance the selectivity of magnetic separation. Also, a lower air flow velocity, which favours the capture of very fine magnetic particles at high magnetic fields, can be utilised in the presence of the matrix vibration.

\subsubsection{The Aperture Size of the Matrix}

The results on the effect of the aperture size of the matrix are shown in Figure 5. A finer matrix with a small aperture $\left(2.5 \times 4.0 \mathrm{~mm}^{2}\right)$ gives a higher iron reduction with a lower $\mathrm{Fe}_{2} \mathrm{O}_{3}$ content of the non-magnetic product. Finer matrix generates a higher field gradient, and thereby a higher attraction magnetic force to capture finer impurity magnetic particles. However, the non-magnetic particles were entrapped in the finer matrix with smaller openings. The mass yield of the non-magnetic product is lower when the expanded metal with a small aperture size is utilised. Clearly, a matrix with a smaller aperture size leads to an increased resistance of the particle-air flow through the matrix. The straining mechanism will become significant and may form a surface mat of the particle deposit on the matrix. In addition, the mechanical entrapment due to the use of the finer matrix reduces the dislodgement of the non-magnetic particles in the particle deposit on the surface of the matrix.

\subsection{A Study of the Mixed Quartz-Hematite Powder}

Figure 6 shows the $\mathrm{Fe}_{2} \mathrm{O}_{3}$ content and the mass yield of the nonmagnetic product as a function of $B_{0} / V_{0}$ for various size fractions of 

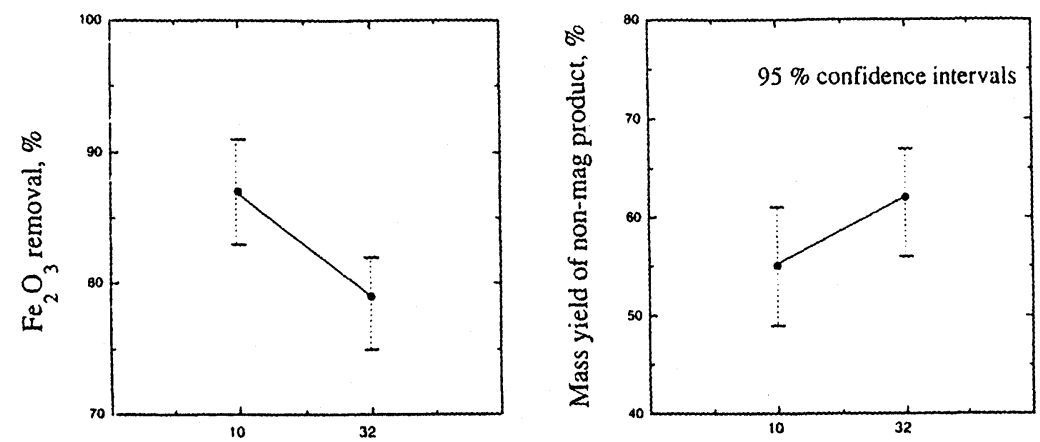

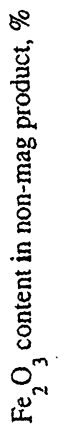
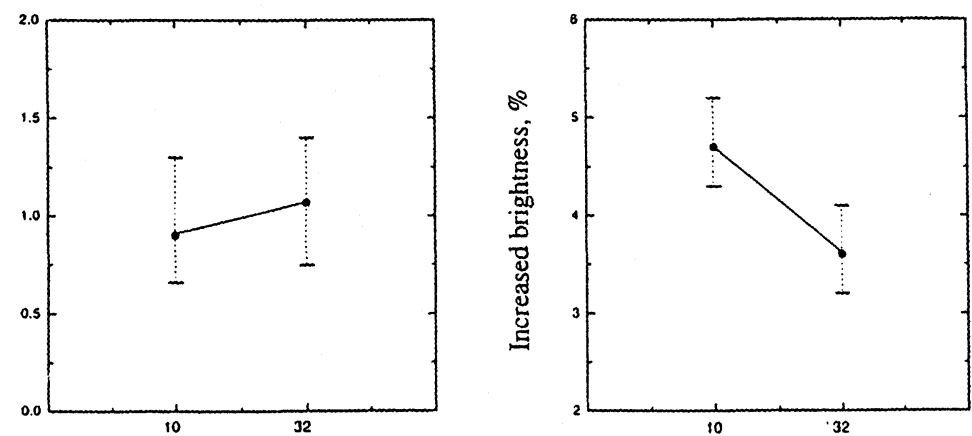

Aperture size of expanded metal matrix, $\mathrm{mm}^{2}$

FIGURE 5 The results of purification of mixed calcite-hematite powder by the CRYOFLOW system with various aperture sizes of the expanded metal matrices.

the mixed quartz-hematite powder. It is seen that the iron content and the mass yield are reduced with the increasing $B_{0} / V_{0}$ for all size fractions. At a higher $B_{0} / V_{0}$, the $\mathrm{Fe}_{2} \mathrm{O}_{3}$ content in the non-magnetic product is reduced to $0.08 \%$ with the mass yield of $90 \%$ for the fraction between 38 and $20 \mu \mathrm{m}$, and to $0.21 \%$ with the mass yield of $80 \%$ for the fraction between $20 \mu \mathrm{m}$ and $10 \mu \mathrm{m}$. The hematite particles smaller than $10 \mu \mathrm{m}$ are not captured efficiently with a finer expanded metal at higher $B_{0} / V_{0}$.

Experiments with and without the matrix vibration were also carried out with two fine sizes of the mixture. Table III shows the results. The mass yield of the non-magnetic product with a lower iron content is dramatically increased for both size fractions with the matrix vibration, compared to that without the matrix vibration. The mass yield reaches $77 \%$ for the fraction between 20 and $10 \mu \mathrm{m}$, and $72 \%$ for the fraction smaller than $10 \mu \mathrm{m}$ in the presence of the matrix vibration. 

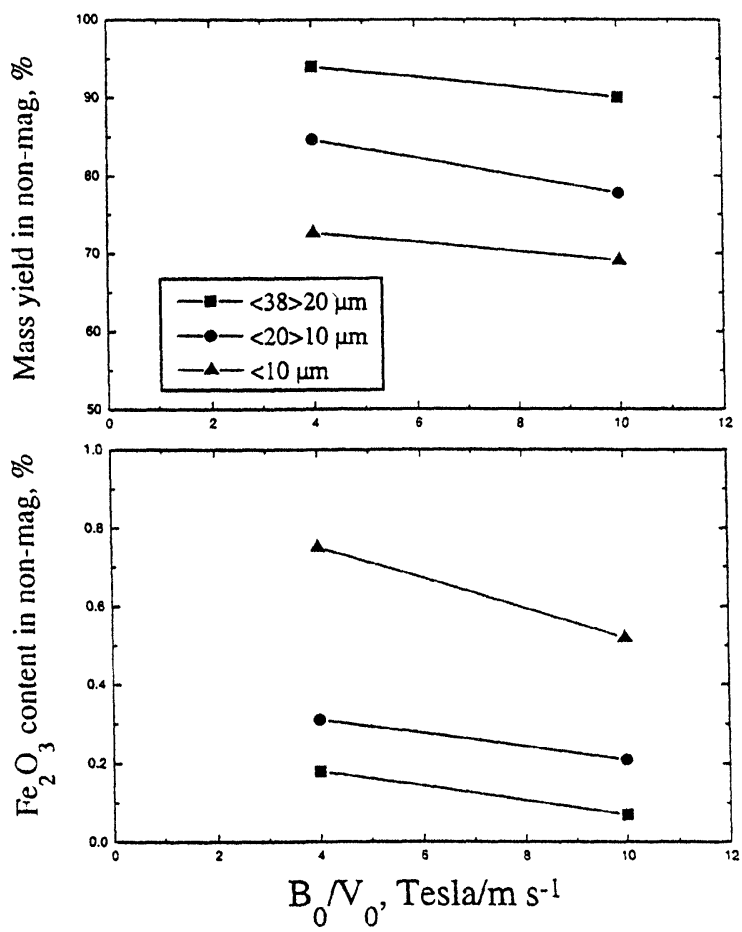

FIGURE 6 The $\mathrm{Fe}_{2} \mathrm{O}_{3}$ content and the mass yield into non-magnetic product as a function of $B_{0} / V_{0}$ for different size fraction of mixed quartz-hematite powders.

TABLE III The results for quartz-hematite mixture powders purified by a superconducting HGMS with or without the vibration assistance

\begin{tabular}{|c|c|c|c|c|c|c|c|}
\hline \multirow{2}{*}{$\begin{array}{l}\text { Size } \\
\text { fraction, } \\
\mu m\end{array}$} & \multirow[b]{2}{*}{ Product } & \multicolumn{3}{|c|}{ No vibration } & \multicolumn{3}{|c|}{ With vibration } \\
\hline & & $\begin{array}{c}\text { Mass } \\
\text { yield, \% }\end{array}$ & $\begin{array}{l}\text { Content } \\
\% \mathrm{Fe}_{2} \mathrm{O}_{3}\end{array}$ & $\begin{array}{c}\text { Distribution, } \\
\quad \% \mathrm{Fe}_{2} \mathrm{O}_{3}\end{array}$ & $\begin{array}{c}\text { Mass } \\
\text { yield, \% }\end{array}$ & $\begin{array}{l}\text { Content, } \\
\% \mathrm{Fe}_{2} \mathrm{O}_{3}\end{array}$ & $\begin{array}{c}\text { Distribution, } \\
\% \mathrm{Fe}_{2} \mathrm{O}_{3}\end{array}$ \\
\hline \multirow{3}{*}{$<20>10$} & Non-mag & & 0.57 & 6.97 & 77.8 & 0.21 & 5.20 \\
\hline & Mag & 61.6 & 4.74 & 93.03 & 22.2 & 13.41 & 94.80 \\
\hline & Feed & 100.0 & 3.14 & 100.00 & 100.0 & 3.14 & 100.00 \\
\hline \multirow{3}{*}{$<10$} & Non-mag & 22.2 & 1.7 & 12.09 & 72.6 & 0.52 & 12.02 \\
\hline & Mag & 77.8 & 3.54 & 87.91 & 27.4 & 10.08 & 87.98 \\
\hline & Feed & 100.0 & 3.14 & 100.00 & 100.0 & 3.14 & 100.00 \\
\hline
\end{tabular}

Also, the $\mathrm{Fe}_{2} \mathrm{O}_{3}$ content of the non-magnetic product is decreased to $0.21 \%$ for the fraction between 20 and $10 \mu \mathrm{m}$ and to $0.52 \%$ for the fraction smaller than $10 \mu \mathrm{m}$, from $3.14 \%$ in the feed. 


\subsection{Comparison of the Results}

Figure 7 shows comparative results from two different powdered mixtures obtained under the same optimum conditions. It is interesting to see that the iron content of the non-magnetic product becomes lower with the higher mass yield when the quartz-hematite mixture is treated. This resultant difference may be related to different characteristics of materials and to the varying adhesive behaviour among particles and between a particle and a wall/matrix element.

The adherence of quartz particles to hematite particles appears weaker, which reduces contamination of the magnetic fraction with quartz particles in dry HGMS, compared to that of calcite particles to hematite particles. A possible explanation for this is that adhesion in different systems due to the tribo-electricity occurs when particles are

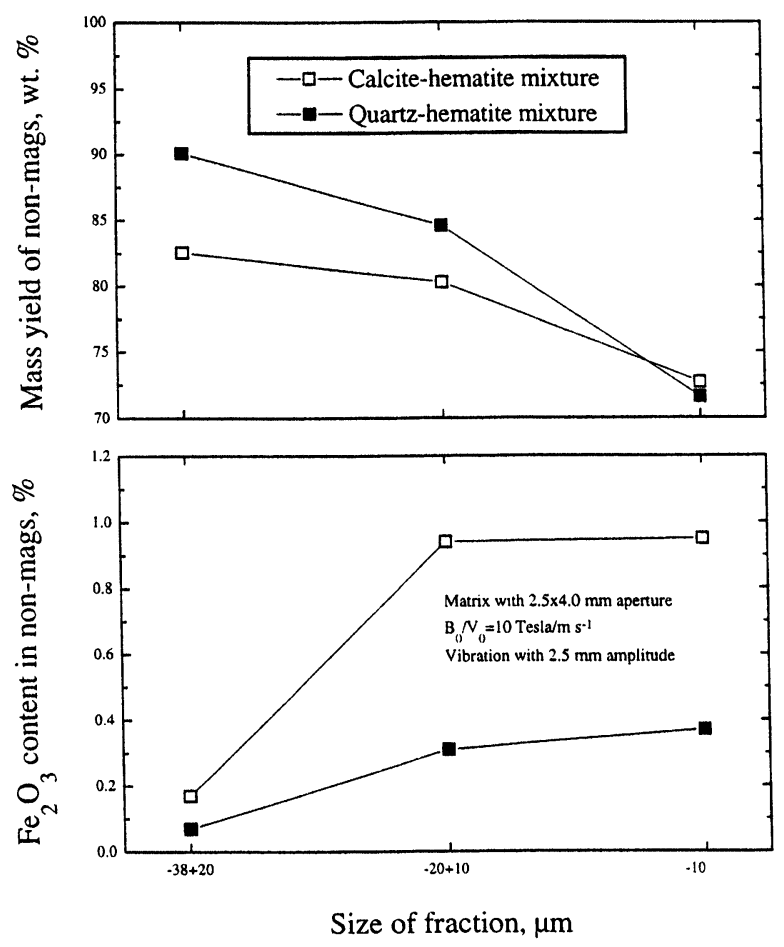

FIGURE 7 The comparative results from two different powdered mixtures obtained under the same optimum conditions. 
preliminarily charged [8]. The charged particles may adhere strongly by a combination of electrostatic and London-van der Waals forces. The charge density in the contact zone reaches values sufficient to have an appreciable effect on the adhesive force. The adhesion depends on the magnitude and the sign of the charges obtained by pouring and blowing [9]. Also, the degree of adhesion may vary even with various magnitudes between different charged particles with the same sign. This may affect the particle trajectories and the powder dynamics through the matrix and the performance of the separator. Some researchers $[10,11]$ found that the average charges of calcite and quartz after tribo-electrification with various material surfaces in the charger are rather different.

\subsection{Empirical Prediction of Performance}

For the purpose of predication empirical models for estimation of the performance of the dry purification of the mixed materials using superconducting HGMS with a matrix vibration system were established from the results. Variables involved were the magnetic field/ average air velocity $\left(B_{0} / V_{0}\right)$, medium size of the particle $\left(\mathrm{F}_{\mathrm{d} 50}\right)$, the aperture size of the expanded metal $(M)$ and the amplitude of vibration with a certain frequency of $50 \mathrm{~Hz}(A)$. No interaction effects were considered due to their insignificant effects. The following estimated models for the iron removal into the magnetic product $(R)$ and the mass yield into the non-magnetic product $(Y)$ can be thus expressed in the treatment of either the calcite-hematite mixture or the quartzhematite mixture, respectively.

For the calcite-hematite mixture,

$$
\begin{aligned}
R= & 74.422+1.429\left(B_{0} / V_{0}\right)+0.658\left(\mathrm{~F}_{d^{50}}\right) \\
& -0.363(M)-1.174(A), \quad\left(R^{2}=66.25 \%\right), \\
Y= & 15.465+0.901\left(B_{0} / V_{0}\right)+0.665\left(\mathrm{~F}_{d^{50}}\right) \\
& +0.397(M)+16.557(A), \quad\left(R^{2}=83.13 \%\right) .
\end{aligned}
$$

For the quartz-hematite mixture,

$$
R=79.95+0.611\left(B_{0} / V_{0}\right)+0.488\left(\mathrm{~F}_{d^{50}}\right)+0.147(A),\left(R^{2}=93.42 \%\right),
$$


$Y=25.28-0.427\left(B_{0} / V_{0}\right)+1.021\left(\mathrm{~F}_{d^{50}}\right)+17.727(A), \quad\left(R^{2}=98.93 \%\right)$.

These empirical models may be appropriate for prediction due to their high correlation indication. These models are primarily valid for the ranges of the parameters used.

\section{SUMMARY}

A superconducting HGMS with a matrix vibrator in dry mode can be used to efficiently remove fine weakly magnetic particles of iron oxide $>20 \mu \mathrm{m}$ from fine powders. Fine hematite particles seem to be relatively easily separated from quartz by the separator, compared to the separation of calcite and hematite particles. The fine particles, especially $<10 \mu \mathrm{m}$, impair the mass yield of the non-magnetic product and the selectivity of the separation due to the effects of inter-particle adhesion and the powder coating on the surfaces of the wall/matrix element. The aspect of varying adhesive behaviour of different powders in dry HGMS is worth of further investigation.

The advantage of using the mechanically based matrix vibration in the dry magnetic purification of fine powders has been demonstrated. This method minimises the clogging effect of the larger aggregates/ clusters in the matrix, releases readily the non-magnetic particles from the particle deposit and removes the non-magnetic particles on the surfaces of matrix/wall. The mass yield into the non-magnetic product with the decreased $\mathrm{Fe}_{2} \mathrm{O}_{3}$ content is dramatically enhanced due to the remission of the particles entrapped mechanically in the matrix by vibration. In the case of the matrix vibration, the mass yield into the non-magnetic product can be increased by $50-75 \%$ with a significant improvement of quality in terms of the $\mathrm{Fe}_{2} \mathrm{O}_{3}$ content of the product. Unsatisfactory iron reduction is mainly related to the effects of finer impure particles in the feed, little or no vibration and a larger aperture size of the expanded metal matrix. The mass yield into the non-magnetic product is significantly influenced by the particle size and the amplitude of vibration, but is independent of the variation of $B_{0} / V_{0}$. 


\section{Acknowledgements}

This work was supported by the Swedish Mineral Processing Research Association (MinFo). The authors thank the Carpco Division, Outokumpu Technology Ltd. for providing the CRYOFLOW separator as well as the corresponding experimental facility, OY Nordkalk, Finland and Norwegian Crystallites, Norway for supplying the material samples. They also thank Mr. Richard Allen from the Carpco Division of Outokumpu Technology Ltd for some discussion and advice during the tests.

\section{References}

[1] Yu, K. C. (1995). The removal of iron from hard-pulverised kaolin by dry highgradient magnetic separation, Magnetic and Electrical Separation, 6(3), 171-177.

[2] $\mathrm{Li}, \mathrm{Z}$. and Veasey, T. J. (1988). An improved process for china clay beneficiation using high-gradient magnetic separation, Minerals Engineering, 1(4), 311-315.

[3] Goodluck, O., Finch, J. and Leroux, M. (1987). Magnetic separation in alternating fields, IEEE Trans. on Mag., MAG. 23(3), 1909-1911.

[4] Svoboda, J., Magnetic methods for the treatment of minerals, Elsevier Science Pub. B.V., 1987.

[5] Sun, Z. and Li, Z. (1985). A study of vibration HGMS, Proc. 15th International Mineral Processing Congress, Cannes, pp. 410-416.

[6] Montgomery, D., Design and analysis of experiments, 3rd edition, John Wiley \& Sons, New York, 1991.

[7] Notenaart, C. W. and Van der Meer, F. P. (1992). High selectivity in HGMS by capture on the downstream side of matrix elements, Minerals Engineering, 5(10-12), 1135-1145.

[8] Zimon, A. D., Adhesion of dust and powder, Plenum Press, New York, 1969.

[9] Bailey, A. G. (1984). Electrostatic phenomena during powder handling, Powder Technology, 37, 71-85.

[10] Chao, T. S., Questions of Engineering Geology and Soil Science, Izd. Mosk. Gos Univ., 1963.

[11] Manouchehri, H. R., Rao, K. H. and Forssberg, E. (1999). Changing potential for the electrical beneficiation of minerals by chemical pre-treatment, Minerals and Metallurgical Processing, 16(3), 14-22. 